\title{
Calculation of Leakage Inductance of Integrated Magnetic Transformer with Separated Secondary Winding Used in ZVS PSFB Converter
}

\author{
Tian Jiashen, Zhang Yiming*, Ren Xiguo, Wang Xuhong, and Tao Haijun \\ College of Electronic Information and Control Engineering, Beijing University of Technology, Beijing 100124, China
}

(Received 7 May 2016, Received in final form 21 November 2016, Accepted 22 November 2016)

\begin{abstract}
A novel zero voltage switching (ZVS) phase shift full bridge (PSFB) converter used in geophysical exploration is proposed in this paper. To extend the ZVS ranges and increase power density of the converter, external inductor acting as leakage inductance is applied and integrated into the integrated magnetic (IM) transformer with separated secondary winding. Moreover, the loss of ZVS PSFB converter is also decreased. Besides, the analysis and accurate prediction methodology of the leakage inductance of the IM transformer are proposed, which are based on magnetic energy and Lebedev. Finally, to verify the accuracy of analysis and methodology, the experimental and finite element analysis (FEA) results of IM transformer and $40 \mathrm{~kW}$ converter prototypes are given.
\end{abstract}

Keywords : Zero voltage switching (ZVS), phase shift full bridge (PSFB), integrated magnetic (IM), leakage inductance, magnetic energy, Lebedev

\section{Introduction}

As high-power DC-DC converter is tending to high frequency and efficiency, power density has become a research target of DC-DC converter in geophysical exploration. Soft-switching technology, which can reduce the electrical stresses and switching losses of switching devices effectively, is the most attractive candidate for high-power DC-DC converter with high frequency [1-4]. However, the primary of transformer applied in softswitching converter usually requires additional resonant inductor, which is large in size and reduces the power density of soft-switching converter. By designing the magnetic circuit rationally, the resonant inductor can be integrated into transformer, named integrated magnetic (IM) transformer. It means that the power density of DCDC converter can be successfully improved [5-9].

In order to obtain larger resonance current and ensure PSFB converter achieve soft-switch in the whole load range, auxiliary legs are added at the leading and lagging legs of the converter in the conventional method. While this method increases the cost and the controlling difficult of zero voltage switching (ZVS) phase shift full bridge

(C)The Korean Magnetics Society. All rights reserved.

*Corresponding author: Tel: 010-67396621

Fax: 010-67396621, e-mail: ymzhang6818@netease.com
(PSFB) converter, due to the additional switching devices, resonant inductors and capacitors at the auxiliary leg [1, 10]. Increasing the resonant inductor at primary of transformer is another effective method to make sure ZVS PSFB converter achieve soft-switch over the whole load condition, this method is simple in topology and convenient in application [11]. However, greater resonant inductance will increase the duty loss of the secondary side waves and decrease the efficiency of ZVS PSFB converter $[12,13]$. In addition, the resonant inductor can be integrated into transformer with integrated magnetic technology [14]. The resonant inductor of ZVS PSFB converter is replaced by IM transformer leakage inductance, and the most common method is increasing leakage inductance layer between the primary and secondary [15]. Leakage inductance layer can also provide sufficient inductance to help ZVS PSFB converter achieve softswitch over the whole load condition [16]. Nevertheless, the leakage inductance layer increases the loss and cost of transformers under full load.

To further improve efficiency and power density of high voltage, high power ZVS PSFB converter, IM transformer with separated secondary winding, which provides sufficient inductance for ZVS PSFB converter, is proposed to take place of the conventional transformer in this paper. Furthermore, the operating principle of the proposed ZVS PSFB converter is analyzed and a calculating 
method of leakage inductance in the IM transformer is proposed based on the energy storage and Lebedev [17]. For particular arrangement of coils has not been realized as pie or layer windings, the inner leakage inductance is difficultly determined through experience formula. By contrast, calculating the inner leakage inductance according to the distribution of the magnetic energy storage is appropriate and accurate. Finally, the experimental and finite element analysis (FEA) results of IM transformer and $40 \mathrm{~kW}$ converter prototypes verify the effectiveness of proposed method and the accuracy of the analysis.

\section{Operational Principle of ZVS PSFB Converter With Separated Secondary Winding}

The core of the IM transformer with separated secondary winding is composed of four C-type nanocrystal blocks, and the area of center leg is double of side leg, as shown in Fig. 1. The primary windings are wound around center leg, and the turns of primary windings are $N_{\mathrm{p}}$. The secondary winding is separated into two parts in order to reduce the voltage stress of secondary rectifier diodes. Transformer secondary side is divided into two subwindings, with number of turns being $N_{\mathrm{s} 11}$ turns (central column) and $N_{\mathrm{s} 12}$ turns (side column) for one sub-winding and being $N_{\mathrm{s} 21}$ turns (central column) and $N_{\mathrm{s} 22}$ turns (side column) for another sub-winding (both central column and side column refer to the magnetic columns of transformer core).

Figure 2 shows the equivalent circuit of the ZVS PSFB converter with separated secondary winding. Based on the integrated magnetic topology, the primary side switching devices have achieved ZVS over the whole load condition, due to the participation of leakage inductance in resonant with capacitors. It is 8 supposing that the main switches (IGBT), diode, inductor and capacitor are all ideal devices and that blocking capacitor has sufficient capacity [2, 18]. Circuit parameters of the converter designed herein are based on the conventional phaseshifted full-bridge converter, where $C_{1}=C_{2}, C_{3}=C_{4}$,

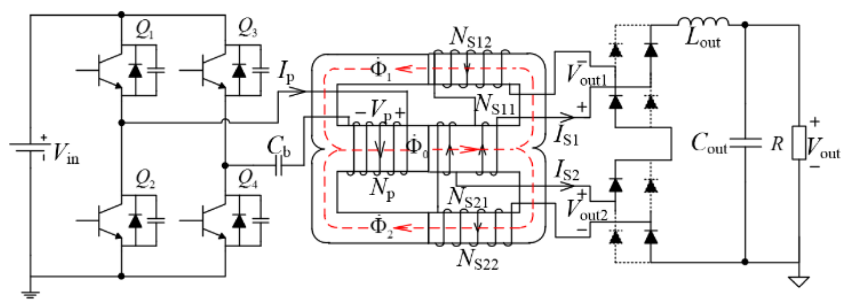

Fig. 1. (Color online) ZVS PSFB Converter with separated secondary winding.

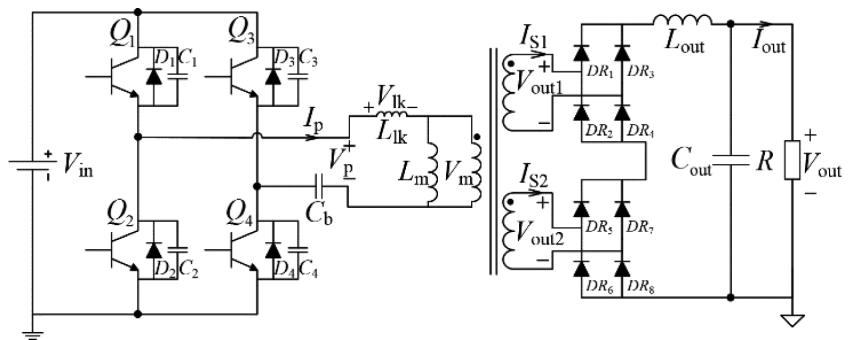

Fig. 2. Circuit diagram of ZVS PSFB converter with separated secondary winding.

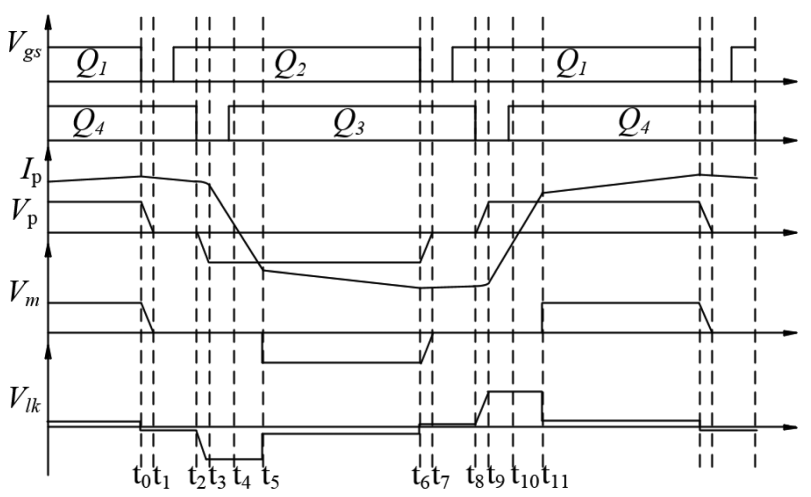

Fig. 3. Main waveforms of ZVS PSFB converter with separated secondary winding.

$n^{2} L_{\text {out }}>>L_{\mathrm{lk}} ; L_{\text {out }}$ is the output inductor; $L_{\mathrm{lk}}$ is the leakage inductance of magnetic integrated transformer; $n$ is the turns ratio of IM transformer; $D_{1}$ to $D_{4}$ and $C_{1}$ to $C_{4}$ are shunt diodes and capacitors across the main switches $Q_{1}$ to $Q_{4}$, respectively; $C_{\mathrm{b}}$ is the blocking capacitor; $D R_{1}$ to $D R_{8}$ are the rectifier diodes; $C_{\text {out }}$ is the output capacitor; $R$ is the equivalent load.

Figure 3 shows the several waveforms and Figure 4 shows all of modes in the operation of ZVS PSFB converter with separated secondary winding. $V_{\mathrm{gs}}$ is the driving voltage of the main switches. $V_{\mathrm{p}}, V_{\mathrm{m}}$, and $V_{\mathrm{lk}}$ are the voltages of primary winding, excitation winding and leakage inductance of the IM transformer, $V_{\text {out1 }}$ and $V_{\text {out2 }}$ are the voltages of the two secondary windings respectively. $I_{\mathrm{p}}$ is the current of the primary winding.

Mode $1\left(0<t<t_{0}\right)$ : Both $Q_{1}$ and $Q_{4}$ are turned on until $t_{0}$. In this mode, the converter outputs power, and the current of $C_{\mathrm{b}}$ is $I_{\mathrm{p}}$.

Mode $2\left(t_{0}<t<t_{1}\right)$. Zero-voltage turning off of $Q_{1}$ can be achieved at time $t_{0}$ when $C_{1}$ and $C_{2}$ resonate with inductor $L_{\mathrm{lk}}+n^{2} L_{\text {out }}$. After time $t_{0}$, the voltage of $C_{1}$ reaches $V_{\text {in, }}$, while the voltage of $C_{2}$ slowly discharges to $0 \mathrm{~V}$.

Mode $3\left(t_{1}<t<t_{2}\right)$. At $t_{1}$ moment, the voltage of $C_{\mathrm{b}}$ is in the maximum value, the voltage across $L_{\mathrm{lk}}$ reverses. $Q_{2}$ is zero-voltage turned on, while $I_{\mathrm{p}}$ conducts through $D_{2}$ and $Q_{4}$. During this interval, $L_{\text {out }}$ is involved in the process 


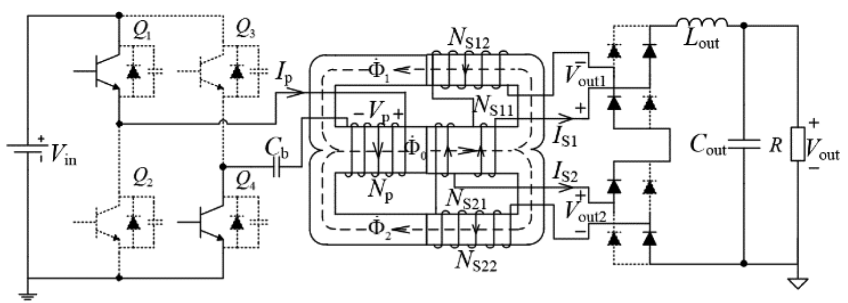

(a) Mode 1

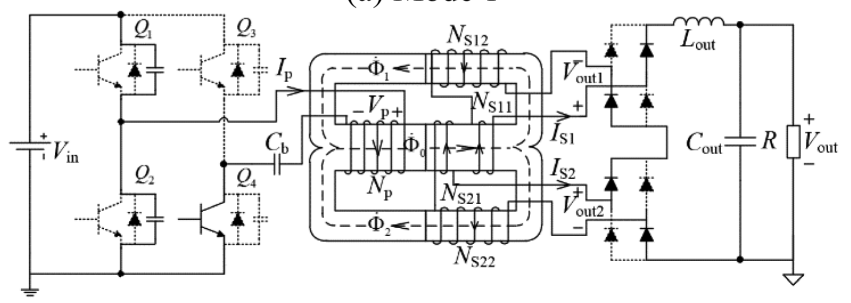

(b) Mode 2

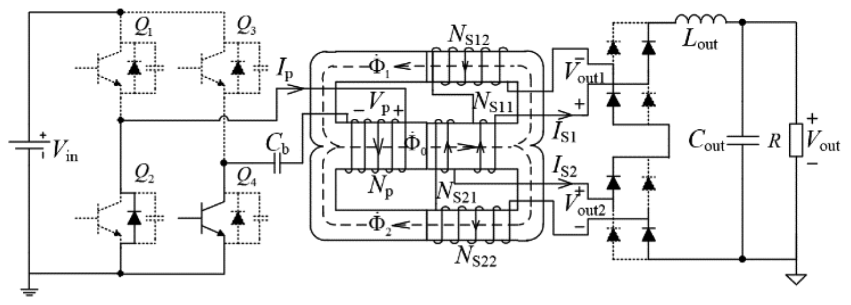

(c) Mode 3

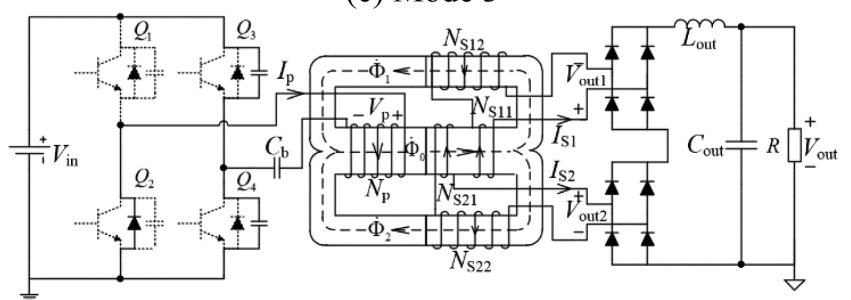

(d) Mode 4

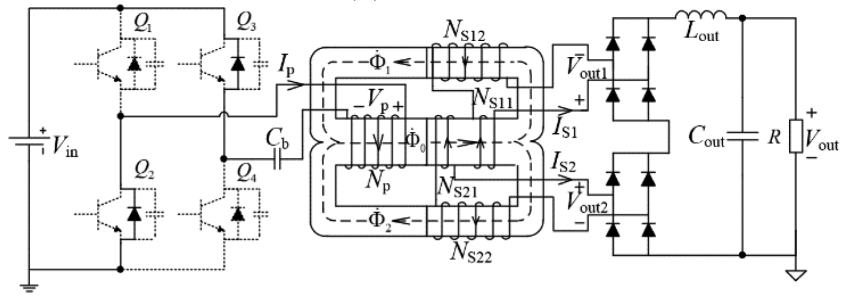

(e) Mode 5

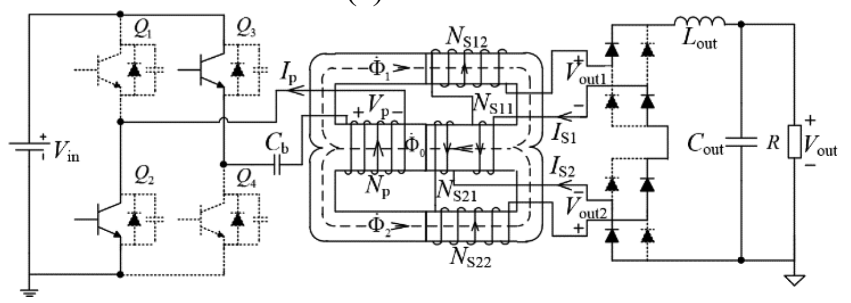

(f) Mode 6

Fig. 4. Operation of proposed converter.

of resonance. Consequently, resonant current is large enough to ensure soft switching of leading legs.

Mode $4\left(t_{2}<t<t_{3}\right), Q_{4}$ is turned off at $t_{2}$. The voltage of $C_{4}$ and $Q_{4}$ rises from zero slowly. Thus, $Q_{4}$ is turned off with zero voltage.

Mode $5\left(t_{3}<t<t_{4}\right)$. While the voltage of $C_{3}$ is discharged to zero and $C_{4}$ is charged to $V_{\text {in }}, I_{\mathrm{p}}$ begins to freewheel through $D_{2}, D_{3}$. In this interval, $I_{\mathrm{p}}$ is quickly dropped to zero.

Mode $6\left(t_{4}<t<t_{6}\right)$. Until the voltage of $C_{4}$ rises to $V_{\text {in, }}$ and $C_{3}$ voltage drops to zero, $Q_{3}$ is turned on with zero voltage. The primary current $I_{\mathrm{p}}$ of the IM transformer reverses after it decreases to zero, $I_{\mathrm{p}}=\left(V_{\mathrm{Cb}}+V_{\mathrm{in}}\right) \Delta t / L_{\mathrm{lk}}$, $C_{\mathrm{b}}$ is charged reversely. Since $I_{\mathrm{p}}$ at this case does not reach the threshold to output, the transformer secondary is still clamped. The converter starts to output at $t_{5} . Q_{2}$ is turned off at $t_{6}$, and the converter starts another half-cycle.

From mode 3 to mode 5, only the leakage inductance of the IM transformer with separated secondary winding involves the resonant with capacitors of the lag switches. In order to make the leg switches to achieve ZVS, the leakage inductance is requested to apply for the following relationship:

$$
\frac{1}{2} L_{l k} I_{p}^{2} \geq 2 \times \frac{1}{2} C_{3} V_{i n}^{2}
$$

where $C_{3}=C_{4}=C^{*}+4 C_{\mathrm{p}} / 3, C^{*}$ is a parallel capacitance of the leg switches, $C_{\mathrm{p}}$ is the parasitic capacitance of IGBT.

From $t_{2}$ to $t_{5}$, the IM transformer with separated secondary winding cannot output. This time is the socalled loss of the duty, expressed as:

$$
D_{\text {loss }}=\frac{2 L_{l k} I_{s}}{n V_{i n} T}
$$

where $I_{\mathrm{s}}$ is the secondary current, $T$ is the switching period. According to the operational principle of ZVS PSFB converter with separated secondary winding, it is observed that excessive leakage inductance will increase the loss of duty cycle as well as reduce the efficiency of the converter. On the opposite, small leakage inductance will increase the difficulty of ZVS. Therefore, accurate calculation of the leakage inductance of the IM transformer is much importance for the proposed ZVS PSFB converter.

\section{Leakage Inductance of Integrated Transformer with Separated Secondary Winding}

The flux distribution of the IM transformer with separated secondary winding is presented in Fig. 5, where $\Phi_{\text {in }}$ is inner leakage flux, $\Phi_{\text {eq }}$ is equivalent leakage flux and $\Phi_{\mathrm{y}}$ is yoke leakage flux. Thus the leakage inductance is composed of three components, which are inner leakage inductance $L_{\text {in }}$ related to $\Phi_{\text {in }}$, yoke leakage inductance $L_{\mathrm{y}}$ 


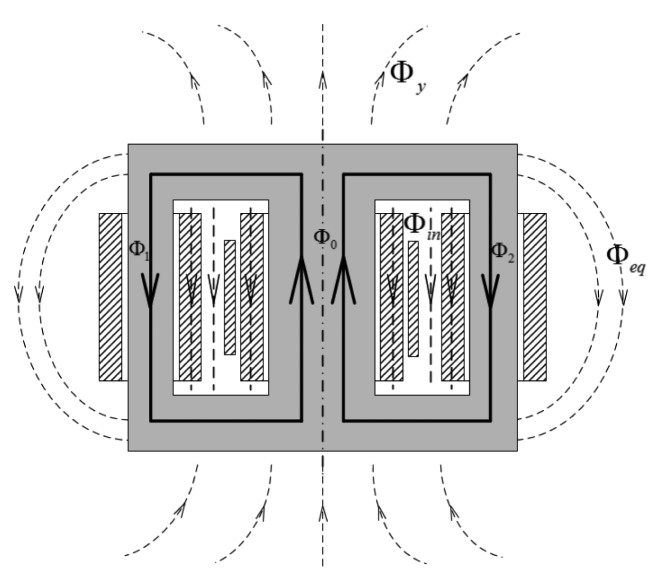

Fig. 5. Magnetic flux distribution of the IM transformer with separated secondary winding.

related to $\Phi_{\mathrm{y}}$, and equivalent leakage inductance $L_{\mathrm{eq}}$ related to $\Phi_{\text {eq }}$. Due to the symmetry of transformer, the total leakage inductance of proposed transformer can be obtained by equation (3).

$$
L_{l k}=2\left(L_{i n}+L_{y}+L_{e q}\right)
$$

\subsection{Calculation of inner leakage inductance $\boldsymbol{L}_{\text {in }}$}

Inner leakage inductance $L_{\text {in }}$ is decided by the allocation of primary windings, secondary windings and window structure of the IM transformer with separated secondary winding.

The $0.18 \mathrm{~mm}$ Litz line is used as windings of the IM transformer, which can eliminate the skin effect and proximity effect at $20 \mathrm{kHz}$ effectively. Thus the magnetic field distribution in high-frequency within half-core window is similar to the distribution in low-frequency $[19,20]$, shown in Fig. 6, where $H(x)$ is the magnetic field intensity and $x$ is the distance along $\mathrm{x}$ axis of core window.

Interval $\left(e_{1} \rightarrow e_{2}\right)$, primary windings $N_{\mathrm{p}}$ are around the
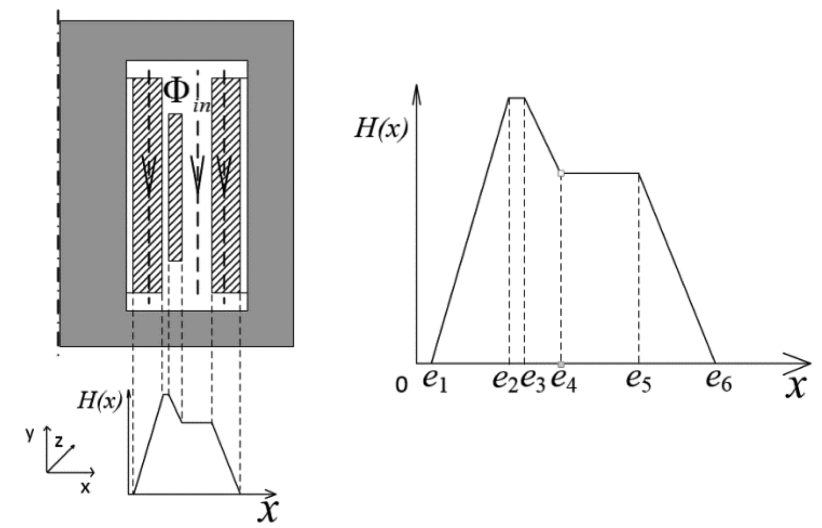

Fig. 6. Leakage flux path and magnetic field distribution within half-core window area. center leg and the magnetic field intensity of half-core window increases from zero to maximum value.

Interval $\left(e_{2} \rightarrow e_{3}\right)$, the magnetic field intensity keeps in maximum value, due to the insulating layer between the primary and secondary windings.

Interval $\left(e_{3} \rightarrow e_{4}\right)$, as $N_{\text {s11 }}$ are wound around the center leg, the magnetic field intensity decreases slightly in this area.

Interval $\left(e_{4} \rightarrow e_{5}\right)$, the magnetic field intensity remains in the air gap between center and side leg.

Interval $\left(e_{5} \rightarrow e_{6}\right)$, since $N_{\mathrm{s} 12}$ are around the side leg, the magnetic field intensity is reduced to zero.

According to the magnetic field intensity distribution of half-core window, $L_{\text {in }}$ can thus be calculated by using the stored magnetic energy, and the relationship can be expressed as following:

$$
W_{\text {in }}=\frac{1}{2} L_{i n} I_{p}^{2}
$$

where $W_{\text {in }}$ is Inner leakage energy.

And also the inner leakage magnetic energy can be expressed as:

$$
W_{\text {in }}=\frac{\mu_{0}}{2} \int H(x)^{2} d v
$$

where $\mu_{0}$ is the permeability of air.

According to the analysis of the magnetic field intensity, the inner leakage energy becomes:

$$
W_{i n}=\frac{1}{2} \mu_{0} l_{w} h_{w} \sum_{i=2}^{6} \int_{e_{i-1}}^{e_{i}} H_{i}(x)^{2} d x
$$

where $l_{\mathrm{w}}$ is the core width along $\mathrm{z}$ axis, $h_{\mathrm{w}}$ is the height of the core window.

Since inner leakage field is divided into five areas, and the energy of each areas can be calculated as follows:

$$
\begin{aligned}
& e_{1} \rightarrow e_{2}: \\
& W_{i n_{-} 1}=\frac{1}{2} \mu_{0} l_{w} h_{w} \int_{0}^{e_{2}-e_{1}}\left[\frac{N_{p} I_{p}}{\left(t_{2}-t_{1}\right) l_{a}} x\right]^{2} d x \\
& e_{2} \rightarrow e_{3}: \\
& W_{i n_{-} 2}=\frac{1}{2} \mu_{0} l_{w} h_{w}\left(\frac{N_{p} I_{p}}{l_{a}}\right)^{2}\left(t_{3}-t_{2}\right) \\
& e_{3} \rightarrow e_{4}: \\
& W_{i n_{-} 3}=\frac{1}{2} \mu_{0} l_{w} h_{w} \int_{0}^{e_{4}-e_{3}}\left(\frac{N_{p} I_{p}-\frac{N_{s 11} I_{s}}{t_{4}-t_{3}} x}{l_{a}}\right)^{2} d x
\end{aligned}
$$




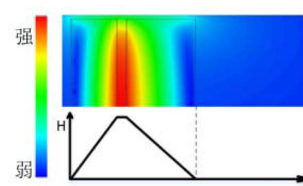

(a)

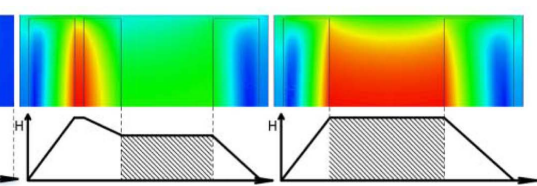

(b)

(c)
Fig. 7. (Color online) FEA of the self-core window for the IM transformer with separated secondary winding.

$$
\begin{aligned}
& e_{4} \rightarrow e_{5}: \\
& W_{\text {in_ } 4}=\frac{1}{2} \mu_{0} l_{w} h_{w}\left(\frac{N_{p} I_{p}-N_{s 11} I_{s}}{l_{a}}\right)^{2}\left(t_{5}-t_{4}\right) \\
& e_{5} \rightarrow e_{6}: \\
& W_{\text {in_5 } 5}=\frac{1}{2} \mu_{0} l_{w} h_{w} \int_{e_{5}}^{e_{6}}\left[-\frac{\frac{N_{s 21} I_{s}}{t_{6}-t_{5}}\left(x-t_{6}\right)}{l_{a}}\right]^{2} d x
\end{aligned}
$$

Based on the stored magnetic energy of leakage inductor, $L_{\text {in }}$ becomes as follows:

$$
L_{\text {in }}=\frac{\sum_{a=1}^{5} W_{\text {in_a }}}{I_{p}^{2}}
$$

In order to verify the analyzing principle of inner leakage inductance distribution, the finite element analysis (FEA) is a candidate, shown in Fig. 7. When the secondary winding is centered on the center leg, the magnetic field intensity in gap area is zero as shown in Fig. 7(a). When the secondary windings are wound around both the center and side leg, the leakage magnetic field will be distributed throughout the half-core window and store large magnetic energy as shown in Fig. 7(b). When all of the secondary windings are wound around the side leg, the magnetic field distribution within the half-core window is shown in Fig. 7(c), and magnetic field stores the largest magnetic energy in the air gap.

Thus, it is obvious that the results of FEA are the same as the theoretical analysis, and inner leakage energy positively correlate in the secondary winding turns $N_{\text {s12 }}$ on side leg.

\subsection{Calculation of yoke leakage inductance $\boldsymbol{L}_{\mathrm{y}}$}

Yoke leakage inductance $L_{\mathrm{y}}$ is mainly associated with yoke leakage flux and correlates with the secondary winding turns $N_{\mathrm{s} 12}$ on side leg. First yoke leakage inductance is calculated at secondary windings and then converted to primary windings. According to Lebedev [17, 21], the formula of yoke leakage inductance at secondary wind- ings $L_{\mathrm{s} \_\mathrm{y}}$ is as follows:

$$
L_{s \_y}=\mu_{0} N_{s 12}^{2} g_{y}
$$

where $g_{\mathrm{y}}$ is a coefficient related to the geometry of the IM transformer with separated secondary winding.

Yoke leakage inductance at primary windings is expressed as:

$$
L_{y}=n^{2} L_{s \_} y
$$

\subsection{Calculation of equivalent leakage inductance $\boldsymbol{L}_{\mathrm{eq}}$}

To calculate the equivalent leakage inductance $L_{\text {eq }}$, it is necessary to firstly calculate the equivalent leakage inductance of secondary winding $L_{\text {s_eq }_{-}}$. $L_{\mathrm{s}_{-} \text {eq }}$ is mainly correlated with the number of turns $N_{\mathrm{s} 12}$, the average turn length of secondary windings $l_{\mathrm{a}}$, core window width along $\mathrm{x}$ axis $b_{\mathrm{w}}$ and core window height $h_{\mathrm{w}}[17,21,22]$. The formula is shown below. $L_{\text {s_eq }}$ is then converted to the primary side to get $L_{\text {eq }}$.

$$
\begin{aligned}
& L_{s_{-} e q}=\frac{\mu_{0} N_{s 12}^{2} l_{a} b_{w}}{3 h_{2}} \\
& L_{e q}=n^{2} L_{s_{-} e q}
\end{aligned}
$$

where $l_{\mathrm{a}}$ is the average turn length of secondary windings.

\section{FEA and Experimental Verifications}

The main parameters of proposed transformer are presented in Table 1. Besides, the magnetic field distribution and total leakage inductance for the IM transformer with separated secondary winding are acquired by FEA, as shown in Fig. 8. The total leakage flux is composed of $\Phi_{\text {in, }} \Phi_{\text {eq }}$ and $\Phi_{\mathrm{y}}$, which conforms to the theoretical analysis at Chapter 3.

Table 2 presents the theoretical calculation, FEA and LCR measurement results of leakage inductance. The value of total leakage inductance $L_{1 \mathrm{k}}$ was calculated using formula (3), and the FEA software (Ansoft Maxwell) was

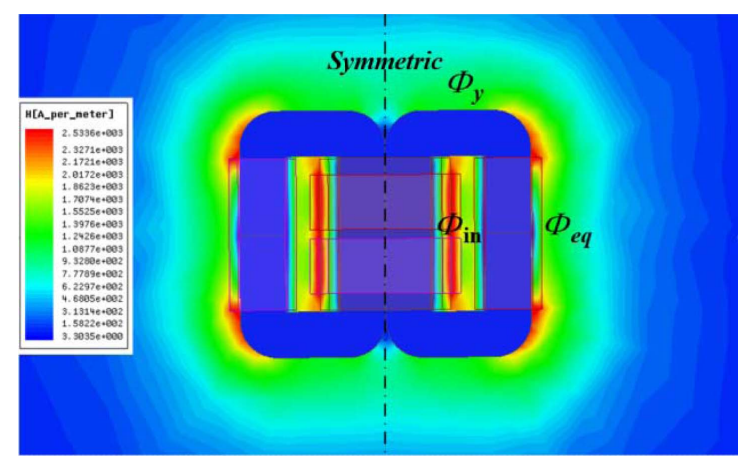

Fig. 8. (Color online) FEA of the IM transformer with separated secondary winding. 
Table 1. IM transformer parameters.

\begin{tabular}{lc}
\hline \hline \multicolumn{1}{c}{ Parameters } & Values \\
\hline Number of turns in primary $\left(N_{\mathrm{p}}\right)$ & 10 \\
Turns ratio $(n)$ & 1.3 \\
Winding material & Litz line \\
Core material & Nanocrystal \\
Area of center leg $\left(A_{\mathrm{c}}\right)$ & $25 \mathrm{~cm}^{2}$ \\
Area of side leg $\left(A_{\mathrm{s}}\right)$ & $12.5 \mathrm{~cm}^{2}$ \\
Core window height $\left(h_{\mathrm{w}}\right)$ & $9 \mathrm{~cm}$ \\
Core window width along x axis $\left(b_{\mathrm{w}}\right)$ & $3 \mathrm{~cm}$ \\
Core width along z axis $\left(l_{\mathrm{v}}\right)$ & $4 \mathrm{~cm}$ \\
Mean turn length in secondary $\left(l_{\mathrm{a}}\right)$ & $20 \mathrm{~cm}$ \\
Insulator thickness $\left(h_{\mathrm{t}}\right)$ & $2 \mathrm{~mm}$ \\
\hline
\end{tabular}

Table 2. Comparison on leakage inductances by the three different methods.

\begin{tabular}{cccc}
\hline \hline $\begin{array}{c}\text { Number of } \\
N_{\text {s12 }}\end{array}$ & $\begin{array}{c}\text { Calculation } \\
(\mu \mathrm{H})\end{array}$ & $\begin{array}{c}\text { FEA } \\
(\mu \mathrm{H})\end{array}$ & $\begin{array}{c}\text { Measurement } \\
(\mu \mathrm{H})\end{array}$ \\
\hline 26 & 42.36 & 43.16 & 42.62 \\
18 & 22.89 & 23.32 & 23.28 \\
10 & 10.6 & 11.13 & 11.23 \\
2 & 4.48 & 5.32 & 5.42 \\
\hline
\end{tabular}

used to calculate the leakage inductance of the transformer. Moreover, experimental values have been measured to evaluate the computational accuracy. For the present IM transformer design showing a closed core and a very high magnetizing inductance, so the short-circuit inductance values which are measured by LCR tester (the inductance measurement at the primary side during short-circuiting the two output terminals of the both secondary sides, measuring frequency $20 \mathrm{kHz}$ ) is closed to the leakage values, and the measured inductance values are considered to be the sought leakage inductance values [23]. Compared with the FEA and experimental results, the error of calculation results is less than $1 \mu H$, which means that the proposed calculation method of leakage inductance are accurate. Moreover, it can be deduced that the value of leakage inductance in the IM transformer with separated secondary winding increases with the increase of turns on side leg.

To ensure ZVS PSFB converter with separated secondary winding achieve ZVS under light load successful, the leakage inductance of prototype should be greater than 20 $\mu \mathrm{H}$. Therefore, the parameters of chosen IM transformer prototype are: $N_{\mathrm{p}}=10, N_{\mathrm{s} 11}=4, N_{\mathrm{s} 12}=18$ and $L_{\mathrm{lk}}=23.28$ $\mu \mathrm{H}$, as shown in Fig. 9. Besides, it is obvious that the total size and weight of the IM transformer with separated secondary winding are half of the conventional transformer and resonant inductance.

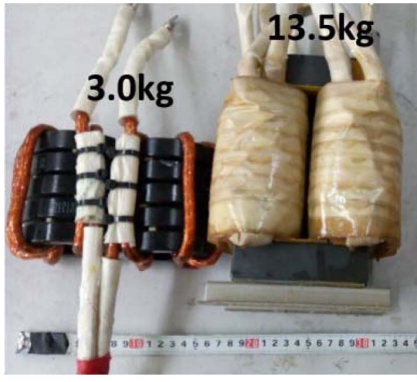

(a)

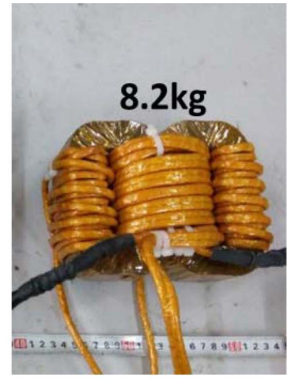

(b)
Fig. 9. (Color online) Comparisons of size and weight between magnetic components. (a) Conventional transformer and resonant inductance. (b) The IM transformer with separated secondary winding.

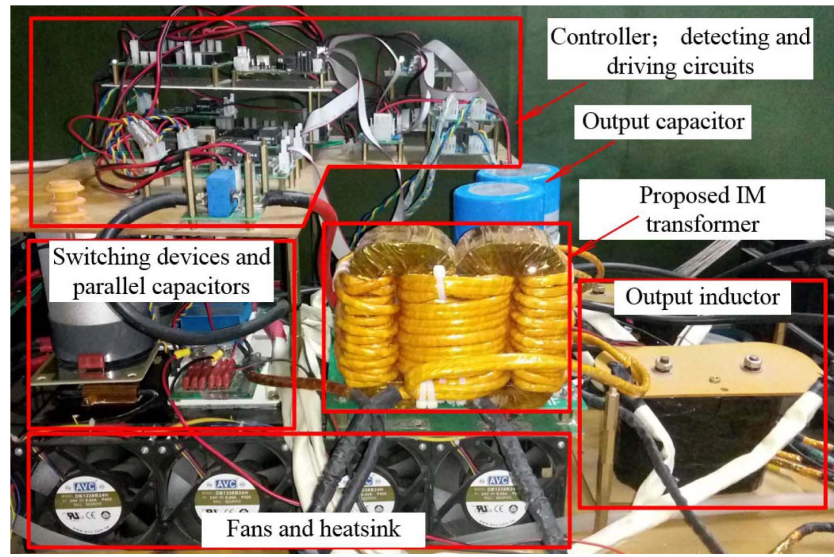

Fig. 10. (Color online) The prototype of proposed ZVS PSFB converter.

The proposed IM transformer is applied to a converter prototype, as shown Fig. 10. For the ZVS PSFB converter with separated secondary winding is designed for a geophysical prospecting equipment, which supplies high power, variable voltage and constant current signals to the earth, converter prototype is implemented with following server power specifications: input voltage $V_{\text {in }}=340-420$ $\mathrm{V}$, output voltage $V_{\text {out }}=200-1000 \mathrm{~V}$, output current $I_{\text {out }}=$ $40 \mathrm{~A}$, switching frequency $f=20 \mathrm{kHz}$, primary switches $Q_{1}-Q_{4}=$ FF300R12KE4, transformer leakage inductance $L_{\mathrm{lk}}=23.28 \mu \mathrm{H}$, high-frequency rectifiers $D R_{1}-D R_{8}=$ DSEI $2 \times 101$, output inductor $L_{\text {out }}=1.6 \mathrm{mH}$, output capacitor $C_{\text {out }}=990 \mu \mathrm{F}$, and Fan $=$ DB 1238B24H $(12 \mathrm{~V}, 21.6 \mathrm{~W}$, $\mathrm{r} / \mathrm{min}=6000)$.

Figure 11 shows the measured efficiency in different load conditions of ZVS PSFB converter with proposed and conventional transformer. Corresponding to $20 \%$ $100 \%$ load conditions, the proposed converter outputs 8 $\mathrm{kW}-40 \mathrm{~kW}$. The input and output power is measured with the norma5000 power analyzer. The PSFB converter with 


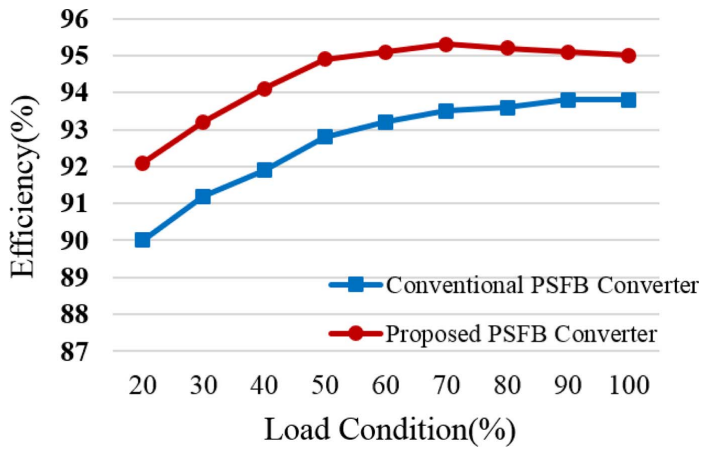

Fig. 11. (Color online) Efficiency comparison with load condition.

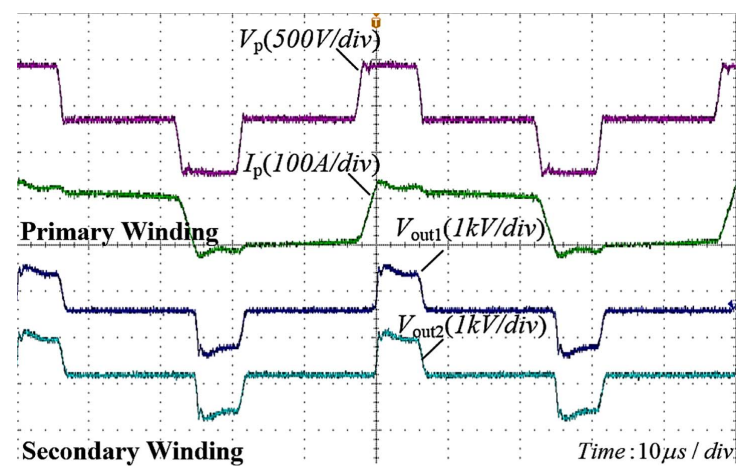

(a)

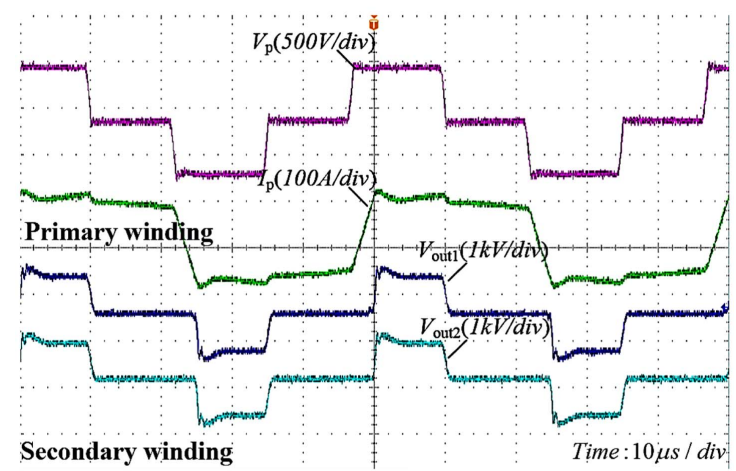

(b)

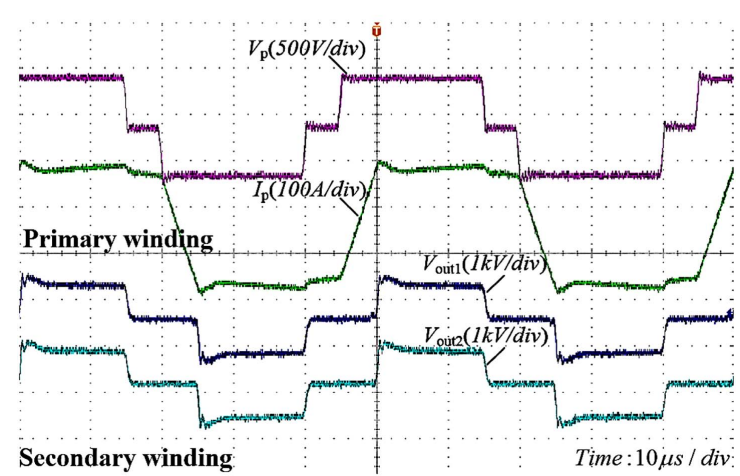

(c)

Fig. 12. (Color online) Waveforms of the proposed IM transformer. (a) $20 \%$ load condition. (b) $50 \%$ load condition. (c) $100 \%$ load condition. proposed transformer shows 1-2 \% higher efficiency than the conventional PSFB converter over entire load conditions. Depending on soft-switching and integrated magnitude technology, the proposed converter reduces the switching loss and remove the high loss inductor of powder core [14, 24, 25].

Figure 12 shows the experimental waveforms of proposed IM transformer over the whole load condition. As shown in Fig. 12(a), soft switching is achieved under 20 $\%$ load despite slight distortions in the primary voltage, primary current and secondary voltage waveform of integrated magnetic transformer isolated from the secondary side, which meets the system design requirements. The waveforms of proposed IM transformer at $50 \%$ and 100 $\%$ load condition are shown in Fig. 12(b) and (c). As shown in Fig. 12(c), the output power of the proposed converter keeps stable at $40 \mathrm{~kW}$, while the loss of duty cycle is within an acceptable range.

\section{Conclusions}

To conclude, the IM transformer with separated secondary winding, which is suitable for ZVS PSFB converter with high power and high voltage, has been proposed in this paper. The calculation method of leakage inductance of the proposed transformer is expressed, and verified by experiment and FEA. Through simply setting the turns on side leg, leakage inductance can be easily designed for the ZVS operation of the proposed converter. Through comparison with conventional converter, the proposed converter increases the efficiency about 1-2 \% at whole load condition, and reduces the size and cost. Therefore, the proposed IM transformer is very desirable for high power, high power density as well as high efficiency ZVS PSFB converter.

\section{Acknowledgement}

This work was supported by R\&D of Instruments and Technologies for Deep Resources Prospecting (the National R\&D Projects for Key Scientific Instruments), Grant No. ZDYZ2012-1-05.

\section{References}

[1] G. Naga and B. Yadav, IEEE Trans. Power Electron. 9, 29 (2014).

[2] S. H. Lee, C. Y. Park, J. M. Kwon, and B. H. Kwon, IEEE Trans. Power Electron. 8, 30 (2015).

[3] K. Shi, D. Zhang, Z. Zhou, M. Zhang, D. Zhang, and Y. Gu, IEEE Trans. Power Electron. 11, 31 (2016). 
[4] J. A. Sabate, V. Vlatkovic, R. B. Ridley, F. C. Lee, and B. H. Cho, Proc. IEEE APEC. (1990) pp. 275-284.

[5] H. Zhu, D. Zhang, Q. Liu, and Z. Zhou, IEEE Trans. Power Electron. 3, 31 (2016).

[6] K. Umetani, IEEJ Trans. Electr. Electron. 1, 7 (2012).

[7] K. Umetani, J. Imaoka, M. Yamamoto, S. Arimura, and T. Hirano, IEEE Trans. Ind. Appl. 1, 51 (2015).

[8] M. Pahlevani, S. Eren, A. Bakhshai, and P. Jain, IEEE Trans. Power Electron. 2, 31 (2016).

[9] Y. Jiang and Z. Chen, IET Power Electron. 3, 5 (2010).

[10] J. G. Cho, J. A. Sabate, and F. C. Lee, Proc. IEEE APEC. (1994) pp. 143-149.

[11] M. Ordonez and J. E. Quaicoe, IEEE Trans. Power Electron. 2, 26 (2011).

[12] R. Ayyanar and N. Mohan, IEEE Trans. Power Electron. 2, 16 (2001).

[13] M. Borage, S. Tiwari, S. Bhardwaj, and S. Kotaiah, IEEE Trans. Power Electron. 4, 23 (2008).

[14] K. M. Cho, Y. D. Kim, I. H. Cho, and G. W. Moon, IEEE Trans. Power Electron. 5, 27 (2012).

[15] B. G. Kang, C. S. Park, and S. K. Chung, Electron. Lett.
10, 50 (2014).

[16] J. M. Choi, B. J. Byen, Y. J. Lee, D. H. Han, H. S. Kho, and G. H. Choe, IEEE Trans. Magn. 11, 48 (2012).

[17] R. Doebbelin and M. Benecke, Power Electron. \& Motion Control Conf. (2008) pp. 1280-1286.

[18] X. Cheng, G. Xie, and F. Deng, IEEJ Trans. Electr. Electron. 2, 11 (2016).

[19] M. A. Bahmani and T. Thiringer, IEEE Trans. Power Electron. 10, 30 (2015).

[20] Z. Ouyang, J. Zhang, and W. G. Hurley, IEEE Trans. Power Electron. 10, 30 (2015).

[21] R. Doebbelin, C. Teichert, M. Benecke, and A. Lindemann, PIERS Online. 5, 8 (2009).

[22] J. C. Maxwell, Lehrbuch der Elektrizitaet und des Magnetismus, Springer-Verlag, 2 (1883).

[23] R. Doebbelin and A. Lindemann, PIERS Procedings. (2010) pp. 5-8.

[24] A. Hilal, M. A. Raulet, C. Martin, and F. Sixdenier, J. Electron. Mater. 10, 44 (2015).

[25] T. Gheiratmand and H. M. Hosseini, J. Magn. Magn. Mater. 19, 408 (2016). 